\title{
Behavior of Prefabricated Structures in Developed and Developing Countries
}

\author{
Omid Reza BAGHCHESARAEI ${ }^{1}$, Hossein Hosseini LAVASANI ${ }^{2 *}$, Alireza BAGHCHESARAEI ${ }^{3}$ \\ ${ }^{1}$ Department of Civil Engineering, Kharazmi University, Tehran, Iran. omidreza@baghchesaraei.com \\ ${ }^{2}$ Assistant professor, Department of Civil engineering, Faculty of Engineering, Kharazmi University, Tehran, Iran. \\ lavasani@khu.ac.ir \\ ${ }^{3}$ Department of Architecture, Bahcesehir University, Istanbul, Turkey. alireza@baghchesaraei.com
}

\begin{abstract}
Today, prefabricated construction has become one of the major components of the developed countries construction and almost 100 percent of building construction utilize prefabricated materials and enormous prefabrication construction showcases in developing countries are in progress and prefabrication construction has shown its potential in development process there too. Although there are numerous advantages connected with developing and prefabricated buildings utilizing prefabrication frameworks, a few constraints can likewise exist. The aim of this research is evaluating different prefabrication technologies and systems in two different categorize (developed countries and developing countries). Prefabrication in construction has the capability to have any kind of effect inside different countries construction industry in monetary, social and ecological terms.
\end{abstract}

Keywords: Prefabrication, Developed countries, Developing countries, Benefits, Limitations

\section{INTRODUCTION}

Prefabrication is the act of collecting segments of a structure in a manufacturing process or other assembling site, and transporting complete congregations or sub-gatherings to the development site where the structure is to be found. The term is utilized to recognize this procedure from the more ordinary development routine of transporting the essential materials to the construction site where all get together is completed.

The ordinary system for constructing a building in prefabrication is to transport blocks, timber, bond, sand, steel and development total, and so forth to the site, and to build the house on site from these materials. In prefabricated construction, just the establishments are developed thusly, while segments of dividers, floors and rooftop are assembled in a processing factory (conceivably with window and door jambs included), transported to the site, lifted into spot by a crane and blasted together.

There are different technologies available worldwide for using prefabrication construction methods, almost all technologies try to reduce costs and time, it means with prefabrication method designers can assembles their favorite structures in a short period of time.

Although designers are allowed to use different kinds of materials, they mostly prefer to choose light weight ones. Wood and steel are the most practical materials in prefabrication construction. Designers should carry out prefabricated buildings by the usage of different technologies and systems, however these technologies need high level of knowledge and experience, so prefabrication construction technologies are so popular in many developed countries in different parts of the world.

Lack of knowledge and experience has caused decreasing in prefabrication construction technologies in many developing countries, but as time goes on several developing countries start using prefabrication by importing its knowledge and technologies. Now a days prefabrication technologies play an important role in multiple developing countries and its usage has been increasing every day.

The aim of this research is evaluating different prefabrication technologies and systems to find out how these systems work in today construction development and how we can use

Prefabrication plays an important role in the modern world construction today, it refers to the making of parts in an offsite workshop or factory prior to the installation at the site. "The primary purpose of prefabrication is to produce building components in an efficient work environment with accesses to specialized skills and equipment in order to reduce cost and time expenditures on the site while enhancing quality and consistency" [1]. Several developing countries are still not familiar with this method. Because those countries have different social and economic systems from modern countries, they tend to use more actual personals for constructions rather than prefabrication methods. 


\begin{abstract}
'Designers should carry out prefabricated buildings by the usage of different technologies and systems, however these technologies need high level of knowledge and experience and high quality of application on site, so prefabricated construction technologies are preferred in many developed countries',[2]. Construction methods that require a lot of physical labor such as masonry, hand paint or cast-in-place concrete are common in several countries. Furthermore, unlike the modern countries, a lot of countries in Asia or Africa may have fewer concerns in many important aspects of building construction, such as preciseness, on-site safety, energy saving and waste management during a construction. All these issues can be resolved by prefabrication methods.
\end{abstract}

\title{
2. METHODOLOGY
}

“The first prefabricated building was built in the 1600' in England and was shipped to Massachusetts ", [3]. For more than a century, prefabrication has been a solid part of construction. Prefabrication is known as a fast and affordable type of construction. After World War II, prefabricated construction became popular for in different countries. "The prefabricated home was not widely used until World War II when mobile homes were produced to supply housing to military personnel" [3]. The need of homes for the men and women who returned to their countries after the war forced builders to build faster. In example, "Eleven million servicemen and -women were returning home to communities where few unoccupied houses were available. By 1947, more than 5 million families had either doubled up with other families in overcrowded dwellings or were occupying temporary shelters" [3]. To meet the high demand, some builders experimented new housing market by creating their own designs and specifications to help build more and faster. Some builders made off-site building components then delivered them to other builders or home buyers rather than building everything at the site. "Many "House by Mails" were shipped from the factories, and the result of big benefit has attracted many new investors" [4]. Since then, many investors have been interested in the prefabrication concept. New factories were built for producing building parts which were then shipped to the site, hence the term "prefabricated construction". "a stick built home is built on site by skilled labor" [5], Today, many architects agree that prefabricated construction makes significant impact on both time and budget, from both the private and public sectors, has been put into research and production to create better prefabricated construction product.

In order to obtain main objectives will be fulfilled by this research, a quantitative research methodology was used for this study. The term 'survey' is commonly applied to a research methodology designed to collect data from different population. Surveys are an important tool for collecting and analyzing information in this study. They are widely accepted as a key tool for conducting and applying basic architectural science research.

The researcher chose a descriptive research methodology and designed a schema to assess the perceptions of different countries works in prefabrication regarding the quality, conditions and facilities in construction through different developed and developing countries (This research consists of two different categories. In the first part prefabricated construction technologies which are available in developed countries evaluated in details. Then, developing countries was the aim of the research and prefabricated construction technologies were evaluated there). The survey items in this study were developed as a result of an analysis of previous studies, discussions with practitioners in the field, and a review of the literature.

After the data was collected it was organized and analyzed. Data was analyzed by using descriptive statistics. Frequency tables were drawn and from these the data was presented in pie diagrams and bar graphs. The information were analyzed through quantitative content analysis by the researcher with the aim of quantifying emerging characteristics and concepts. Concept analysis is the process of analyzing verbal or written communications in a systematic way to measure variables quantitatively [6].

These results showed how prefabrication technologies and systems can help to different countries construction development.

\section{PREFABRICATION TECHNOLOGY AND SYSTEMS IN PREFABRICATED BUILDINGS}

Prefabrication is a development industry term used to depict assemblies that are fabricated under processing factory conditions and afterward transported to development destinations for joining into building and structural designing works.

Precast said of a concrete member that is cast and cured in other than its final position [7]. In construction, a structure gathered from arranged segments that don't require extra treatment, for example, cutting or fitting, at the building site. The segments of prefabricated structures are fabricated of different materials, for instance, steel, concrete, reinforced concrete, wood, asbestos bond, aluminum composites, and plastics, in specific plants of the development business or in on site yards. 
Prefabricated structures are suitable only in the case of high-volume use of individual prefabricated components and a minimum number of standard sizes of those components. For this reason, provision is made for the predominant use of standardized parts (principally, large-size items) in prefabricated construction.

Prefabricated structures may also be demountable, depending on the type of connections used. This is very efficient in the erection of various temporary structures, especially in regions with difficult access.

"Prefabricated structures are suitable just on account of high-volume utilization of individual prefabricated segments and a base number of standard sizes of those parts. Therefore, procurement is made for the overwhelming utilization of institutionalized parts (principally, large-size items) in prefabricated construction" [8].

Prefabricated structures might be demount capable, contingent upon the kind of associations utilized. This is exceptionally proficient in the erection of different transitory structures, particularly in districts with difficult access.

Prefabricated structures constitute a noteworthy division of the building stock in many developed and developing countries. Depending on the load-bearing structure and prefabricated systems, it described in four different types which can be divided into the following categories:

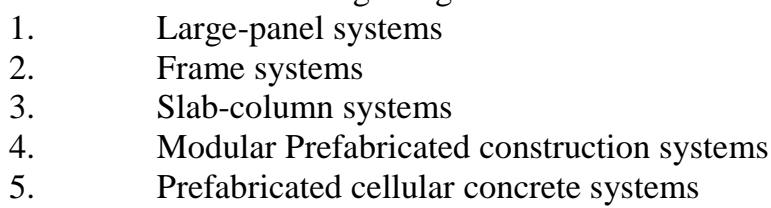

\section{PREFABRICATION CONSTRUCTION MARKET}

In 1950's, the prefabrication knowledge started to import to different countries. Designers and contractors tried to detect a specific schema for prefabricated buildings market, since there are different kinds of methods were available and they promoted their knowledge to make the market ready for their works and products. In last decades as time goes on, different problems occurred in construction issues and in many developed countries the governments chose prefabricated buildings as one of their solutions in construction. However the prefabrication market has not been the same in different countries but it illustrates, different market schema in different developed countries but almost in all developed countries it displays rapid increase in tough periods of time such as Second World War (Fig. 1).

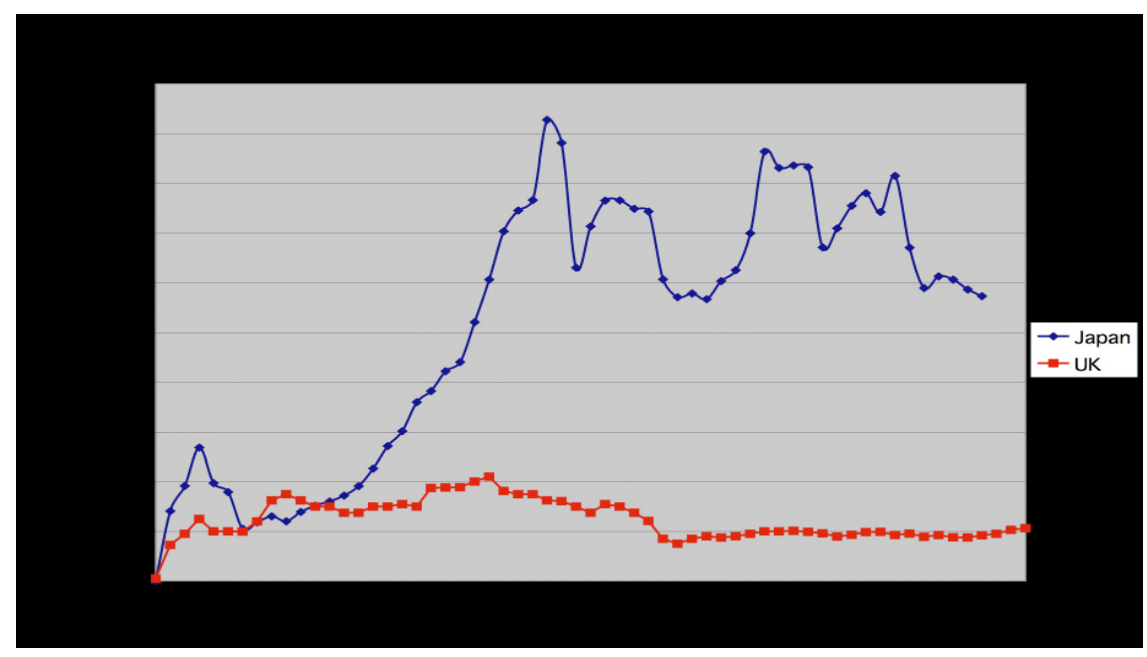

Fig.1. Prefabricated buildings completion in Japan and the UK in last 50 years

In the past, the prefabrication market focused mostly on home's market. Today, the market has extended to other building commercial ventures that incorporate health awareness, instruction, and business structures. Around $85 \%$ of respondents are utilizing these procedures to outline and develop those business ventures at a few levels in developed countries (Smart Market Reports: McGraw-Hill Construction, 2011). Still, the largest prefabrication market is the housing market. "Prefabricated housing can be categorized into modular, mobile (HUD code), production builder, and panelized [9]. Below is the market share:

1. 63 percent of all new housing is being built by builders/dealers.

2. 56 percent is panelized.

$3 . \quad 33$ percent production is onsite building.

4. 7 percent is modular.

5. 4 percent is HUD-code mobile. 
Three main categories of prefabrication (panelized, production builders, and modular) appear to be the most prevalent construction for prefabricated buildings nowadays since the site work and development advance expenses are soaring. In any case, the prefabricated industry has been confronting the down-turn due to the subprime contract emergency that began in 2007.

The future market of prefabrication can be seen as the improvement of the current business sector and the new development pattern market. At first, the construction's idea was a technique for building quicker and all the more monetarily. The early construction extends basically were moderate tasks, for example, reasonable homes on site that early engineers attempted to get up to speed with the high lodging interest with a profoundly productive method for construction. Today, construction is not just being seen as a development strategy for moderate activities however it has additionally ventured into the extravagance market. Creating top notch building parts from a processing factory will exceptionally basic in near future. Since the innovations of large scale manufacturing for customer items will grow quick, these advances can help build the nature of building components to a higher standard.

The new development business sector incline additionally affects the future of construction. These new development patterns such as: Lean Construction, BIM, and Green Building, will fortify the prefabrication market in near future, since they will minimize waste of materials, time, and effort in order to generate the maximum possible amount (Fig. 2).

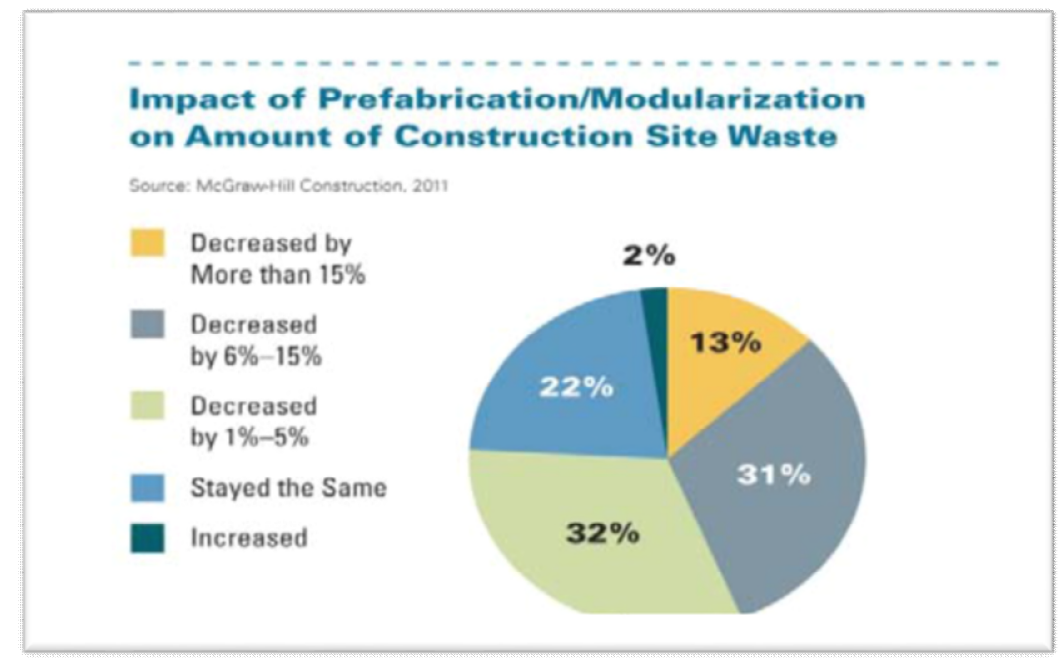

Fig.2. Impact of Prefabrication on Amount of Construction Site Waste in developed countries

\section{BENEFITS AND LIMITATIONS OF PREFABRICATION}

There are numerous potential advantages related when delivering and developing building by prefabrication. The accompanying segments have been separated under two headings keeping in mind the end goal to intelligently introduce these thoughts. The construction assembly advantages components will basically consider upgrades connected with the real gathering of prefab frameworks, though the assembling advantages area will look at the preferences emerging from the generation of these frameworks in a controlled manufacturing factory setting. Site-constructed development is utilized as a base of examination among systems, and subjective information from the construction is incorporated to backing the justification.

Using prefabrication in a project allows the time dealing with site to be decreased. This implies that the effect of the site on the nearby environment is for a shorter time of time. Site work is customarily defenseless against interruption from extremes of climate, by utilizing construction the site will be powerless for less time thus the danger of deferral and prerequisites for assurance will be lessened for a given task. Some significant retail customers are effectively focusing on persistent decrease in the site advancement time with a general lessening of 50\% in venture time being accepted to be a sensible objective, construction is a dynamic piece of the procedure that will help to convey these investment funds.

Where prefabrication is being utilized as a part of a task it is imperative to incorporate it in the process as ahead of schedule as could be expected under the circumstances, and preferably at idea outline stage [5]. Issues of absence of similarity and coming about expanded expenses are regular where pre-assembled parts are not considered until later all the while. Construction obliges that all included in the process experience an expectation to absorb information to 
upgrade the advantages of utilizing the framework. Changing the configuration of a progressing venture that uses preassembled parts presents a scope of issues for realignment as segments are by and large conveyed to site to fit a particular arrangement of measurements. Attempting to more prominent accuracy with great supervision ought to diminish the measure of change and realignment that is important. Development IT co-appointment can possibly guarantee that arrangement and accuracy are kept up both on location and in the manufacturing environmental prefabrication activities.

Although there are numerous advantages connected with developing and assembling buildings utilizing prefabrication frameworks, a few constraints can likewise exist. The majority of the concerns emerge from transportation issues confronted by the prefabricated buildings industry.

There is a general concern among the quake designing group regarding to the seismic execution of prefabrication construction. Taking into account involvement in past seismic tremors in Eastern European and in Central Asian nations where these frameworks have been generally utilized, it can be presumed that their seismic execution has been genuinely palatable. Be that as it may, in terms of seismic tremor execution, the truth of the matter is that "terrible news" is more generally announced than "uplifting news." For example, the poor performance of precast frame systems of Seria 111 in the 1988 in Armenia earthquake is well known (Fig. 3). However, few designers are aware of the good seismic performance (no damage) of several large-panel buildings under construction at the same site (Fig. 4).

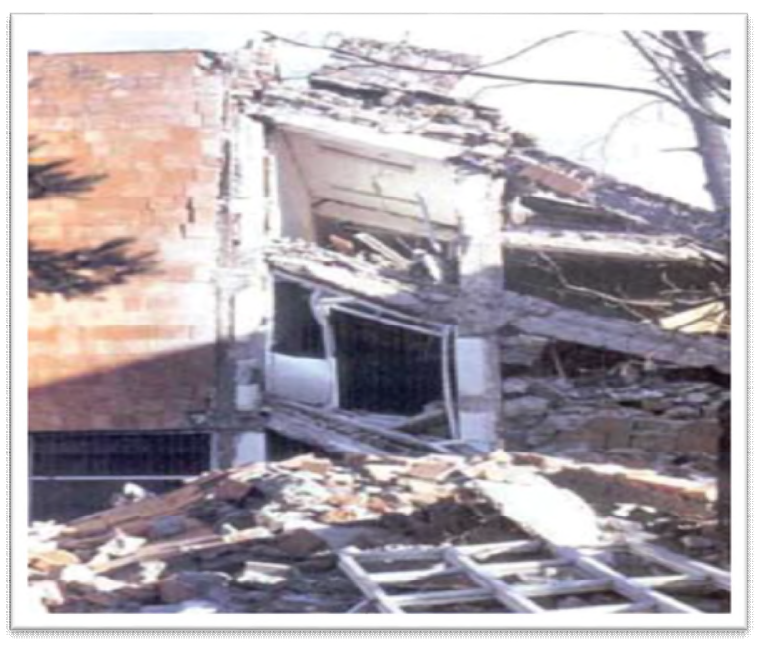

Fig. 3. Building collapse in the 1988 in Armenia

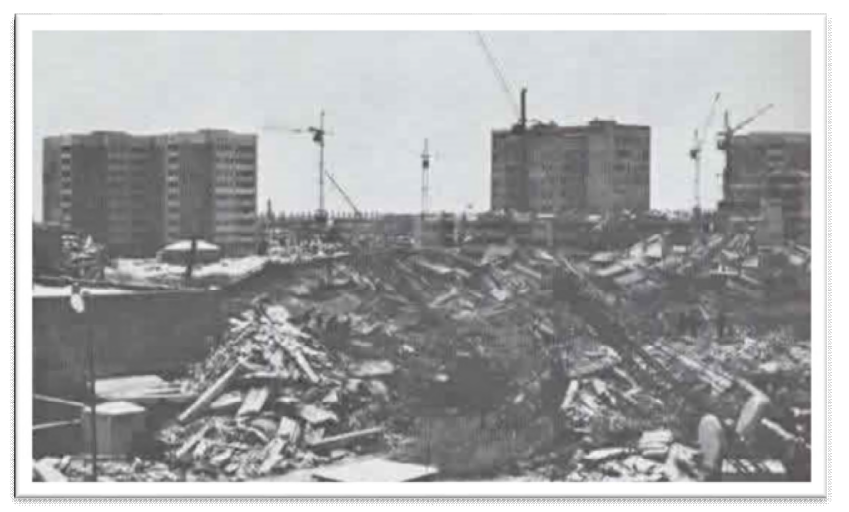

Fig. 4. Large-panel concrete buildings remained undamaged in 1988 in Armenia

\section{CONCLUSION}

Prefabrication is a settled acquisition choice in most of developed countries. There are, nonetheless, a scope of boundaries to its maximum capacity use which originate from past experience of prefabrication which have abandoned it marked as a low quality item with related social disgrace. Prefabrication inside the residential market is most influenced by this discernment, yet offers extensive open door for those willing to utilize it legitimately. 
Bulletin de la Société des Sciences de Liège, Vol. 85, 2016, p. 1229 - 1234

The benefits of using prefabrication in developing countries:

1. Higher quality products for clients.

2. Improved productivity and profitability for contractors.

3. Environmental benefits associated with its use.

Table 1. Comparison between developed and developing countries in prefabrication impact (Now)

\begin{tabular}{|c|c|c|}
\hline \multicolumn{3}{|l|}{ Prefabrication impact summary } \\
\hline Impact & Developed countries & Developing countries \\
\hline Lower initial costs & + & + \\
\hline Reduced environmental impacts & + & - \\
\hline Reduced time & + & + \\
\hline Improved health and safety & + & - \\
\hline Reduced defects & + & - \\
\hline Improved economic security & + & + \\
\hline Reduced waste & + & + \\
\hline
\end{tabular}

There are various evidences cited by industry wellsprings of the potential investment funds that could be made with frameworks, then again, minimal autonomous evaluation of genuine execution has been made. Such autonomous affirmation of genuine execution attributes is required keeping in mind the end goal to beat the impression of parts of the prefabrication that construction is a low quality substitute for conventional development approaches. The following phase of this venture will concentrate on adding to this level of data from specific contextual analyses of prefabricated development and equivalent traditional construction.

\section{REFERENCES}

[1] Anderson, M and Anderson, P. (2007). Prefab prototypes: site specific design for offsite construction. Princeton Architectural Press. New York : NY

[2] Baghchesaraei, A., Kaptan, M and Baghchesaraei, O.R. (2015). Using Prefabrication Systems in Building Construction.' International Journal of Applied Engineering Research ISSN 0973-4562.

[3] Kim, T. (2009). Comparison of prefab homes and a site-built home: Quantitative evaluation of four different types of prefab homes and a site-built home. University of Souther California.

[4] Arieff, A. and Burkhart, B. (2002). Prefab. Salt Lake City: Gibbs Smith.

[5] Fetters, T. (2002). The Lustron home. Jefferson, N.C.: McFarland.

[6] Phillipson, M., Scotland, B. R. E., and Lane, B. (2001). Defining the Sustainability of Prefabrication and Modular Process in Construction 36/08/328 cc2114 Interim.

[7] Baghchesaraei, A and Baghchesaraei, O.R. (2014). Essential words for Architects and Structural Engineers. Naghoos Publication. Tehran.

[8] Best, R., \& De Valence, G. (2002). Design and construction: Building in value. Routledge.

[9] Smith, Ryan E. (2010).Prefab Architecture: A Guide to Modular Design and Construction. Wiley, Hoboken: NJ. 